\title{
MULTI-PERIOD PRODUCTION PLANNING UNDER FUZZY CONDITIONS
}

\author{
Naadimuthu, G. ${ }^{*}$ : Liu, Y.L.. ${ }^{* *}$ \& Lee, E.S. ${ }^{* *}$ \\ ${ }^{*}$ Fairleigh Dickinson University, Madison, NJ 07940, USA \\ **Kansas State University, Manhattan, KS 66506, USA \\ E-mail: naadi@fdu.edu
}

\begin{abstract}
:
In the real-world multi-period production/operations management (MP-POM) problems, the parameters must be estimated and they are frequently given by interval estimates. But for most POM models, these interval estimates must be translated into single numbers. This often results in errors and in the loss of a considerable amount of information. The purpose of this paper is to develop, apply, and illustrate a new fuzzy approach using fuzzy numbers to solve the interval MP-POM problem. It consists of employing appropriate fuzzy numbers to represent the interval estimates in the multi-stage decision problems; using the operations of fuzzy numbers combined with dynamic programming to solve the problem; and determining the required minimum/maximum fuzzy number through ranking techniques. To demonstrate the application of this approach, three MP-POM problems with fuzzy costs and/or fuzzy demands are solved. The main advantages of this approach are fuzzy representative solutions for the optimal production schedule and the minimum total cost in terms of interval units rather than single numbers. This enables the production engineers and operations managers to manage the production flexibly and control the costs effectively. A significant original contribution of this research is the development of an effective technique to solve the fuzzy MP-POM problems that have not been addressed thus far. Suggestions for future research include extending the proposed general fuzzy approach to solve large scale multistage fuzzy problems using computers; and to solve problems with fuzzy goals and constraints defined in different spaces.
\end{abstract}

Key Words: Multi-period Production Planning, Multi-period Production/Operations Management (MP-POM), Fuzzy Conditions, Scalar Demands, Fuzzy Demands, Scalar Costs, Fuzzy Costs, Crisp Dynamic Programming (CDP), Fuzzy Dynamic Programming (FDP)

\section{INTRODUCTION}

Production/operations management (POM) has a significant impact on the economy of most firms. Because of its multi-period nature, POM must be planned before the beginning of production. However, the exact information needed is not available until the production events occur. So in multi-period POM (MP-POM) problems, the future parameters must be estimated. A frequently used method is to give them interval (range) estimates. For almost all models, these interval estimates must be translated into single numbers. This may result not only in errors, but also in the loss of a considerable amount of information. Since fuzzy numbers can be used to overcome these difficulties, they offer an ideal approach for solving real-world MP-POM problems.

The main purpose of this study is to find an effective method to solve the interval MPPOM problems, while retaining all the original information. The proposed technique is a general fuzzy multi-stage decision approach based on fuzzy numbers using a problemoriented point of view. The effectiveness of this approach is illustrated through its application to solve three different fuzzy MP-POM problems - fuzzy costs and scalar demands; fuzzy demands and scalar costs; and fuzzy costs and fuzzy demands. The three MP-POM models 
are solved by both the proposed fuzzy approach and the current crisp methods. The results are compared and contrasted to show the advantages of the proposed procedure.

\section{LITERATURE SURVEY}

There have been many publications in literature on MP-POM. Corsano et al. [1] presented a multi-period mixed integer nonlinear optimization model for multiproduct batch plants under seasonal and market fluctuations. Neiro and Pinto [2] optimized multi-period production planning models by mixed integer nonlinear programs under uncertain conditions of prices and demands. Safaei and Tavakkoli-Moghaddam [3] proposed an integrated mathematical model of the multi-period cell formation and production planning in a dynamic cellular manufacturing system to minimize costs through a mixed integer programming technique. Porkka et al. [4] used a mixed integer linear programming based capacitated lot sizing models that included carryovers incorporating set-up times with associated costs. Moreno et al. [5] employed a general multi-period optimization model for multi-product batch plants to maximize an economic function consisting of incomes and costs using mixed integer linear programming. Moreno and Montagna [6] utilized a linear general disjunctive programming model for multi-period production planning in a multi-product batch environment to maximize the expected net present value of the benefit under uncertainty in demands.

El Hafsi and Bai [7] determined an optimal multi-period production plan for a single product over a finite planning horizon to minimize the total inventory and backlog costs by solving a nonlinear programming problem. Feylizadeh [8] integrated project management network and mathematical programming techniques to decrease the total cost by controlling the completion time in a multi-period multi-product production planning problem. Li et al. [9] derived an optimal solution structure by the dynamic programming approach for a joint manufacturing and remanufacturing system in a multi-period horizon.

Yildirim et al. [10] devised a rolling-horizon approach based on solving the static problem at each time period for a stochastic multi-product production planning and sourcing problem. Filho [11] provided a stochastic optimization model with constraints on the production and inventory variables for a multi-product multi-period long-term production planning problem through Gaussian approximation.

Kaminsky and Swaminathan [12] developed heuristics that utilize knowledge of demand forecast evolution for capacitated multi-period production planning. Kazancioglu and Saitou [13] applied a simulation based method to aid multi-period production capacity planning using a multi-objective genetic algorithm. Sox and Muckstadt [14] formulated an algorithm using Lagrangian relaxation for the finite horizon capacitated multi-period production planning problem with random demand for multiple products. Nagasawa et al. [15] introduced two algorithms, one with stationary demand and the other with seasonal demand, for determining the value of generalized planning horizon based upon a property of an analytical solution to a multi-period production planning problem.

Kogan and Portougal [16] focused on the control decisions for multi-period aggregate production planning to minimize the expected total costs. Balakrishnan and Cheng [17] addressed cellular manufacturing under conditions of multi-period planning horizons with demand and resource uncertainties. Ryu [18] illustrated through numerical examples multiperiod planning strategies with simultaneous consideration of demand fluctuations and capacity expansion.

The above publications on MP-POM required precise or stochastic data. However, in real life the data are usually available in imprecise terms. A realistic and better way to represent these imprecise data is to use fuzzy numbers. Thus, this situation in reality is a fuzzy problem. This paper attempts to solve the fuzzy MP-POM problem through the application of fuzzy multi-stage decision making processes. 


\section{PROBLEM DESCRIPTION AND SOLUTION METHODOLOGY}

Let the production cost in period t be

$$
K\left(P_{t}\right)=\left\{\begin{array}{lll}
0 & \text { if } & P_{t}=0 \\
A_{t}+c_{t} P_{t} & \text { if } & P_{t}>0
\end{array}\right.
$$

and the inventory holding cost in period t be

$$
K\left(I_{t}\right)=h_{t} I_{t}
$$

Then the general MP-POM problem becomes:

Minimize

$$
C_{T}=\sum_{t=1}^{T}\left(A_{t}+c_{t} P_{t}+h_{t} I_{t}\right)
$$

Subject to

$$
\begin{aligned}
& I_{t}=I_{t-1}+P_{t}-D_{t} \\
& 0 \leq P_{t} \leq P_{\text {Max }} \\
& 0 \leq I_{t} \leq I_{\text {Max }} \\
& t=1,2, \ldots, T-1, T
\end{aligned}
$$

where

$C_{t}=$ total cost of production and inventory with the management horizon $t=1$ to $T$

$A_{t}=$ fixed production cost in period $t$

$c_{t}=$ variable unit production cost in period $t$

$h_{t}=$ unit inventory holding cost in period $t$

$\mathrm{P}_{\mathrm{t}}=$ production in period $\mathrm{t}$

$\mathrm{P}_{\mathrm{Max}}=$ maximum production capacity

$D_{t}=$ forecasted demand in period $t$

$I_{t}=$ inventory at the end of period $t$

$I_{\text {Max }}=$ maximum inventory capacity

This problem can be solved by dynamic programming (DP). Based on the following properties of optimal solution

$$
\begin{aligned}
& I_{t-1} P_{t}=0 \\
& P_{t}=0, D_{t}, D_{t}+D_{t+1}, D_{t}+D_{t+1}+D_{t+2}, \ldots, D_{t}
\end{aligned}
$$

Wagner and Whitin (1958) developed a more effective MP-POM model using DP. In this model the total cost of production and inventory over the period $\mathrm{j}$ to $\mathrm{k}$ is:

$$
C_{j k}=k\left(P_{j k}\right)+k\left(I_{j k}\right)=A_{j+1}+c_{j+1} P_{j+1}+\sum_{t=j+1}^{k-1} h_{t} I_{t}
$$

where $C_{j k}=$ cost of production and inventory in period $j+1$ to satisfy demand in $j+1, j+2, \ldots, k$. The global optima can be obtained by the following DP recursive equation:

$$
Z_{k}=\min _{0 \leq j \leq k-1}\left[Z_{j}+C_{j k}\right] \quad(k=1,2, \ldots, T)
$$

At each stage of the recursion, we seek to minimize the combination of the cost of production and inventory between two regeneration points ( $\mathrm{j}$ and $\mathrm{k}$ ) and the optimal program up to $\mathrm{j}$. The recursion is computed for $\mathrm{k}=0$ to $\mathrm{T}$.

In the real world MP-POM problem, the amounts of $A_{t}, c_{t}, h_{t}$, and $D_{t}$ are estimated based on experience, expected value or other statistical techniques. These amounts must be approximated by single numbers, when we solve the problem by crisp DP. This type of approximation always loses some information. A better choice is to represent the estimated amounts by the use of fuzzy numbers. In this project, we solve three MP-POM problems with 
estimated costs and demands by applying the general fuzzy approach based on the use of fuzzy numbers. Specifically, we develop fuzzy MP-POM models by: (a) using appropriate triangular fuzzy numbers to represent the interval estimates $A_{t}, c_{t}, h_{t}, D_{t}$ in equation (4); (b) employing the fuzzy number operations '(+)' and '(.)' to carry out the corresponding operations ' + ' and '. ' in equations (4) and (5); and (c) applying the fuzzy number ranking method to complete the 'min' problems by both the crisp and fuzzy models. Then we compare the results to evaluate the advantages of the proposed fuzzy MP-POM approach over the current crisp approaches.

\section{MP-POM PROBLEM WITH FUZZY COSTS AND SCALAR DEMANDS}

Let us consider a firm making a production plan for a product over a management horizon of three periods with zero initial inventory. The information for this problem is given in Table I.

Table I: The information of this problem.

\begin{tabular}{|l|ll|l|l|l|l|}
\hline period $t$ & $\begin{array}{l}\text { demand } \\
\text { (units) }\end{array}$ & $\mathrm{D}_{\mathrm{t}}$ & $\begin{array}{l}\text { setup cost } \\
(\$ 1000)\end{array}$ & $\mathrm{A}_{\mathrm{t}}$ & $\begin{array}{l}\text { unit cost } \mathrm{C}_{\mathrm{t}} \\
(\$ 1000 / \mathrm{unit})\end{array}$ & $\begin{array}{l}\text { holding cost } \\
(\$ 1000 / \text { unit/period })\end{array}$ \\
\hline 1 & 10 & $(15,20,50)$ & $\mathrm{h}_{\mathrm{t}}$ \\
\hline 2 & 30 & $(20,40,50)$ & $(2,3,6)$ & 1 \\
\hline 3 & 30 & $(20,30,60)$ & $(\mathrm{l}, 3,4)$ & 1 \\
\hline
\end{tabular}

In this table, the setup costs and variable unit costs are given by triangular fuzzy numbers representing the interval estimates.

\subsection{Solution by Crisp Dynamic Programming (CDP)}

To obtain the optimal production schedule by CDP, we translate the estimated numbers into single numbers as shown in Table II.

Table II: To obtain the optimal production schedule by CDP.

\begin{tabular}{|l|l|l|l|l|}
\hline$t$ & $D_{t}$ (units) & $A_{t}(\$ 1,000)$ & $c_{t}(\$ 1000)$ & $h_{t}(\$ 1000)$ \\
\hline 1 & 10 & 20 & 3 & 1 \\
\hline 2 & 30 & 40 & 3 & 1 \\
\hline 3 & 30 & 30 & 3 & 2 \\
\hline
\end{tabular}

In the above table, the most possible numbers are chosen as the approximated single numbers of the estimated intervals; all the other information is lost.

Following the Wagner and Whitin [19] approach, we obtain:

$$
\begin{aligned}
& Z_{1}=C_{01}=A_{1}+c_{1}\left(D_{1}\right)=20+3(10)=50 \\
& Z_{1}^{*}=50 \\
& Z_{2}=Z_{0}+C_{02}=A_{1}+c_{1}\left(D_{1}+D_{2}\right)+h_{1}\left(D_{2}\right)=20+3(10+30)+1(30)=170 \\
& \text { Or } Z_{2}=Z_{1} *+C_{12}=Z_{1} *+A_{2}+c_{2}\left(D_{2}\right)=50+40+3(30)=180 \\
& Z_{2} *=170 \\
& Z_{3}=Z_{0}+C_{03}=A_{1}+c_{1}\left(D_{1}+D_{2}+D_{3}\right)+h_{1}\left(D_{2}+D_{3}\right)+h_{z}\left(D_{3}\right) \\
& =20+3(10+30+30)+1(30+30)+1(30)=320 \\
& \text { Or } Z_{3}=Z_{1} *+C_{13}=Z_{1} *+A_{2}+c_{2}\left(D_{2}+D_{3}\right)+h_{2}\left(D_{3}\right)=50+40+3(30+30)+1(30)=300 \\
& \text { Or } Z_{3}=Z_{2} *+C_{23}=Z_{2} *+A_{3}+c_{3}\left(D_{3}\right)=170+30+3(30)=290 \\
& Z_{3} *=290
\end{aligned}
$$

The minimum total cost is $\$ 290,000$. The production schedule (Table III) is found by tracing the solution backwards. 


$$
\begin{aligned}
& Z_{3}^{*}=290 \quad \text { Produce } 30 \text { units in period } 3 \text { for period } 3 . \\
& Z_{2}^{*}=170 \quad \text { Produce } 40 \text { units in period } 1 \text { for both periods } 1 \text { and } 2 .
\end{aligned}
$$

Table III: The production schedule.

\begin{tabular}{|l|l|l|l|}
\hline Period & 1 & 2 & 3 \\
\hline Production & 40 & 0 & 30 \\
\hline
\end{tabular}

\subsection{Solution by Fuzzy Dynamic Programming (FDP)}

Now the fuzzy numbers are employed to replace the translated single numbers in the above problem; to obtain the optimal production schedule by FDP, we use the general fuzzy approach and the Wagner and Whitin [19] approach. Using the data of Table I, we obtain:

$$
\begin{array}{rl}
Z_{1} & =C_{01}=A_{1}(+) c_{1}(.) D_{1}=(15,20,50)(+)(2,3,6)(.) 10=(35,50,110) \\
Z_{1} & =(35,50,110) \\
Z_{2} & =Z_{0}(+) C_{02}=A_{1}(+) c_{1}(.)\left(D_{1}+D_{2}\right)+h_{1}\left(D_{2}\right) \\
& =(15,20,50)(+)(2,3,6)(.) 40+1(30)=(125,170,320) \\
\text { Or } Z_{2}= & Z_{1}(+) C_{13}=Z_{1}(+) A_{2}(+) c_{2}(.) D_{2} \\
& =(35,50,110)(+)(20,40,45)(+)(1,3,4)(.) 30=(85,180,275) \\
\mu & (125,170,320)=205 \\
\mu & (85,180,275)=180 \\
180 & <205 ;(85,180,275)<(125,170,320) \\
& * \\
Z & =Z \quad(+) C_{13}=(85,180,275) \\
2 & 1 \\
Z_{3} & =Z_{0}(+) C_{03}=A_{1}(+) c_{1}(.)\left(D_{1}+D_{2}+D_{3}\right)+h_{1}\left(D_{2}+D_{3}\right)+h_{2}\left(D_{3}\right) \\
= & (15,20,50)(+)(2,3,6)(.) 70+60+30=(245,320,560) \\
\text { Or } Z_{3}=Z_{1} *(+) C_{13}=Z_{1} *(+) c_{2}(.)\left(D_{2}+D_{3}\right)+h_{2}\left(D_{3}\right) \\
\quad=(35,50,110)(+)(20,40,45)(+)(1,3,4)(.)(30+30)(+) 1(30)=(145,300,425) \\
\text { Or } Z_{3}=Z_{2} *(+) C_{23}=Z_{2} *(+) A_{3}(+) c_{3}(.) D_{3} \\
\quad=(85,180,275)(+)(20,30,60)(+)(2,3,5)(.)(30)=(165,300,485) \\
\mu\left(Z_{0}(+) C_{03}\right)=\mu(245,320,560)=375 \\
\mu\left(Z_{1}(+) C_{13}\right)=\mu(145,300,425)=290 \\
\mu\left(Z_{2}(+) C_{23}\right)=\mu(165,300,485)=316 \\
Z_{3}=(145,300,425) \\
3
\end{array}
$$

The production schedule (Table IV) is obtained by tracing the optimal fuzzy solution backwards.

$$
\begin{array}{ll}
Z_{3}^{*}=(145,300,425) & \text { Produce } 60 \text { units in period } 2 \text { for periods } 2 \text { and } 3 . \\
Z_{1}^{*}=(35,50,110) & \text { Produce } 10 \text { units in period } 1 \text { for period } 1 .
\end{array}
$$


Table IV: The production schedule.

\begin{tabular}{|l|l|l|l|}
\hline Period & 1 & 2 & 3 \\
\hline Production & 10 & 60 & 0 \\
\hline
\end{tabular}

\subsection{Comparison of the Two Solutions}

The production schedules obtained by CDP are different from those obtained by FDP. The total cost $(205,290,530)$ by CDP is more than that $(145,300,425)$ by FDP (Figure 1). This difference in the above example is predicated upon whether a single crisp number or a fuzzy interval is used for $A_{1}$. Obviously it is more practical to specify that the estimated amount $A_{1}$ is about $\$ 20,000$ with an upper limit of $\$ 50,000$ and a lower limit of $\$ 15,000$, as indicated by the fuzzy number $A_{1}=(15000,20000,50000)$, rather than by a single number $A_{1}=20,000$. Thus the production schedule obtained by FDP is more realistic than that obtained by CDP. Also, the production engineers or operations managers would require exactly $\$ 290,000$, as per the schedule obtained by the crisp model. However, this is not the case, since the minimum total cost should be $(205,290,530)$ thousand dollars in order to satisfy the forecasted demand of the management horizon.

This fuzzy cost indicates that the total production cost is about $\$ 290,000$, with an upper limit of $\$ 529,000$ and a lower limit of $\$ 206,000$. This will enable the production manager to give appropriate leeway for the total cost in the budget.

Furthermore, the schedules obtained by the crisp and the fuzzy models are not necessarily different. In this example, the fuzzy number operations used are (i) addition of a scalar and a triangular fuzzy number; (ii) addition of two triangular fuzzy numbers; and (iii) multiplication of a triangular fuzzy number and a scalar. If all the fuzzy costs in the problem are symmetrical triangular fuzzy numbers and the demands are scalars, then the results after applying the above three operations are still symmetrical triangular fuzzy numbers, as proven by Kaufman and Gupta [20]. The main part of fuzzy number ranking method is the generalized mean, and the generalized mean of any symmetrical triangular fuzzy number, $M$ $=(a, b, c)$, is $c$; hence, if all costs in the POM problem are represented by symmetrical triangular fuzzy numbers or scalars, then the schedule obtained by the fuzzy model should be the same as that obtained by the crisp model. Thus the fuzzy model is an alternative to having to use single numbers in multi-period production planning. It provides a comparable or better schedule than the crisp model.

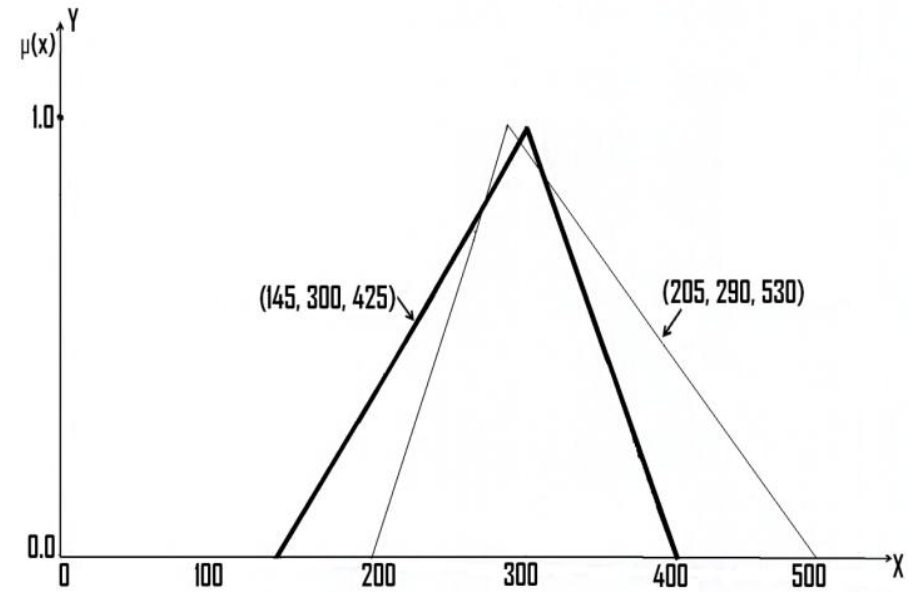

Figure 1: Cost Comparison of Two Different Schedules.

\section{MP-POM PROBLEM WITH FUZZY DEMANDS AND SCALAR COSTS}

The data for this problem are given in Table $V$. In this example, the forecasted demands are fuzzy numbers, while the costs $c_{t}, A_{t}$ and $h_{t}$ are scalars. 
Table V: The data for this problem.

\begin{tabular}{|l|l|l|l|l|}
\hline $\mathrm{t}$ & $D_{t}$ & $\mathrm{~A}_{\mathrm{t}}(\$ 1000)$ & $\mathrm{C}_{\mathrm{t}}(\$ 1000)$ & $\mathrm{h}_{\mathrm{t}}(\$ 1000)$ \\
\hline 1 & $(5,10,20)$ & 20 & 3 & 1 \\
\hline 2 & $(25,30,40)$ & 40 & 3 & 1 \\
\hline 3 & $(20,20,40)$ & 30 & 3 & 2 \\
\hline
\end{tabular}

\subsection{Solution by Crisp Dynamic Programming (CDP)}

If we translate the estimated demands into single numbers and solve the problem by the Wagner and Whitin [19] approach, the data remain the same as shown in Table II, and the optimal schedule also remains the same as shown in Table III.

\subsection{Solution by Fuzzy Dynamic Programming (FDP)}

Here again, we combine the general fuzzy approach with Wagner and Whitin [19] approach and use all of the information given in Table 5 to solve this MP-POM problem.

$$
\begin{aligned}
& Z_{1}=C_{01}=A_{1}(+) c_{1}(.) D_{1}=(20)(+) 3(.)(5,10,20)=(35,50,80) \\
& Z_{1}^{*}=(35,50,80) \\
& Z_{2}=Z_{0}(+) C_{02}=A_{1}(+) c_{1}(.)\left[D_{1}(+) D_{2}\right](+) h_{1}(.)\left[D_{1}(+) D_{2}(-) D_{1}\right] \\
& \quad=(20)(+) 3(.)[(5,10,20)(+)(25,30,40)](+)[(5,10,20)(+)(25,30,40)(-)(5,10,20)] \\
& \quad=(120,170,255)
\end{aligned}
$$

Or $Z_{2}=Z_{1}(+) C_{12}=Z_{1}(+) A_{2}(+) c_{2}(.) D_{2}$

$$
\begin{aligned}
& =(35,50,80)(+) 40(+) 3(.)(25,30,40)=(150,180,240) \\
& \mu\left(Z_{0}(+) C_{02}\right)=545 / 3
\end{aligned}
$$$$
\mu\left(Z_{1}(+) C_{12}\right)=570 / 3
$$$$
Z_{2}^{*}=\left(Z_{0}(+) C_{02}\right)=(120,170,255)
$$$$
Z_{3}=Z_{0}(+) C_{03}=A_{1}(+) c_{1}(.)\left[D_{1}(+) D_{2}(+) D_{3}\right](+) h_{1}(.)\left[D_{1}(+) D_{2}(+) D_{3}-D_{1}\right]
$$$$
(+) h_{2}(.)\left[D_{1}(+) D_{2}(+) D_{3}(-) D_{1}(-) D_{2}\right]
$$$$
=20(+) 3(.)[(5,10,20)(+)(25,30,40)(+)(20,30,40)]
$$$$
(+)[(5,10,20)(+)(25,30,40)(+)(20,30,40)(-)(5,10,20)]
$$$$
(+)[(5,10,20)(+)(25,30,40)(+)(20,30,40)(-)(5,10,20)(-)(25,30,40)]
$$

$$
=(190,330,485)
$$

$$
\begin{aligned}
& \text { Or } Z_{3}=Z_{1}^{*}(+) C_{13}=Z_{1}^{*}(+) A_{2}(+) c_{2}(.)\left[D_{2}(+) D_{3}\right](+) h_{2}(.)\left[D_{2}(+) D_{3}(-) D_{2}\right] \\
& \quad=(35,50,80)(+) 40(+) 3(.)[(25,30,40)(+)(20,30,40)] \\
& \quad(+)[(25,30,40)(+)(20,30,40)(-)(25,30,40)] \\
& \quad=(215,300,415) \\
& \text { Or } Z_{3}=Z_{2}^{*}(+) C_{23}=Z_{2}^{*}(+) A_{3}(+) c_{3}(.) D_{3}
\end{aligned}
$$$$
=(120,170,255)(+) 30(+) 3(.)(20,30,40)=(210,290,405)
$$ 


$$
\begin{aligned}
& \mu\left(Z_{0}^{*}(+) C_{03}\right)=1025 / 3 \\
& \mu\left(Z_{1}^{*}(+) C_{13}\right)=930 / 3 \\
& \mu\left(Z_{2}^{*}(+) C_{23}\right)=905 / 3 \\
& Z_{3}^{*}=\left(Z_{2}^{*}(+) C_{23}\right)=(210,290,405)
\end{aligned}
$$

The production schedule (Table $\mathrm{VI}$ ) is obtained by tracing the optimal fuzzy solution backwards.

Table VI: The production schedule.

\begin{tabular}{|l|l|l|l|}
\hline Period & 1 & 2 & 3 \\
\hline Production & $(30,40,60)$ & 0 & $(20,30,40)$ \\
\hline
\end{tabular}

$Z_{3}^{*}=\left(Z_{2}^{*}(+) C_{23}\right)=(210,290,405)$; Produce $D_{3}=(20,30,40)$ units in period 3 for period 3.

$\left.Z_{2}^{*}=Z_{0}(+) C_{02}\right)=(120,170,255) ;$ Produce $D_{1}(+) D_{2}$ units in period 1 for both periods 1 and 2 .

\subsection{Comparison of the Two Solutions}

In this example, the results obtained by CDP and FDP are quite different. The production schedule obtained by the fuzzy model is represented by fuzzy numbers, which retain all the original information; but the schedule obtained by the crisp model is represented by a single number, which lost most of the original information. Also, the minimum total costs obtained by the crisp and the fuzzy models are similarly different.

The above two differences are important and useful in practice. According to the schedule obtained by the crisp model, the firm must produce exactly 40 units in period 1 and 30 units in period 3 . However, in practice, this may not be necessary; also, it may require additional production time leading to increase in cost.

\section{MP-POM PROBLEM WITH FUZZY COSTS AND FUZZY DEMANDS}

For this case, we consider a two-period production management problem as shown in Table VII. In this example, all costs and demands are given by interval estimates.

Table VII: A two-period production management problem.

\begin{tabular}{|l|l|l|l|l|}
\hline$t$ & $D_{t}$ (units) & $A_{t}(\$ 1000)$ & $c_{t}(\$ 1000)$ & $h_{t}(\$ 1000)$ \\
\hline 1 & $(20,30,60)$ & $(20,30,40)$ & $(1,4,6)$ & $(1,2,3)$ \\
\hline 2 & $(30,50,60)$ & $(20,40,50)$ & $(2,3,5)$ & $(1,3,4)$ \\
\hline
\end{tabular}

\subsection{Solution by Crisp Dynamic Programming (CDP)}

The translated scalar costs and demands are given in Table VIII. 
Table VIII: The translated scalar costs and demands.

\begin{tabular}{|l|l|l|l|l|}
\hline $\mathrm{t}$ & $\mathrm{D}_{\mathrm{t}}$ & $\mathrm{A}_{\mathrm{t}}$ & $\mathrm{C}_{\mathrm{t}}$ & $\mathrm{h}_{\mathrm{t}}$ \\
\hline 1 & 30 & 30 & 4 & 2 \\
\hline 2 & 50 & 40 & 3 & 3 \\
\hline
\end{tabular}

$$
\begin{aligned}
& Z_{1}=C_{01}=A_{1}(+) c_{1}\left(D_{1}\right)=30+4(30)=150 \\
& Z_{1}^{*}=150 \\
& Z_{2}=C_{02}=A_{1}+c_{1}\left(D_{1}+D_{2}\right)+h_{1}\left(D_{2}\right)=30+4(30+50)+2(50)=450 \\
& \text { Or } Z_{2}=Z_{1}^{*}+C_{12}=Z_{1}^{*}+A_{2}+c_{2}\left(D_{2}\right)=150+40+3(50)=340
\end{aligned}
$$

The optimal schedule is shown in Table IX.

Table IX: The optimal schedule.

\begin{tabular}{|l|l|l|}
\hline Period & 1 & 2 \\
\hline Production & 30 & 50 \\
\hline
\end{tabular}

\subsection{Solution by Fuzzy Dynamic Programming (FDP)}

$$
\begin{aligned}
& Z_{1}^{*}=C_{01}=A_{1}(+) c_{1}(.) D_{1} \\
& =(20,30,40)+(1,4,6)(.)(20,30,60) \\
& =\left\{\begin{array}{lc}
0, & x \leq 40 \\
{\left[-80+(1600+120 x)^{0.5}\right] / 60,} & 40 \leq x \leq 150 \\
{\left[310-(100+240 x)^{0.5}\right] / 120,} & 150 \leq x \leq 400 \\
0, & x \geq 400
\end{array}\right. \\
& Z_{2}=Z_{0}(+) C_{02}=A_{1}(+) c_{1}(.)\left[D_{1}(+) D_{2}\right](+) h_{1}(.)\left[D_{1}(+) D_{2}(-) D_{1}\right] \\
& =(20,30,40)(+)(1,4,6)(.)[(20,30,60)(+)(30,50,60)](+)(1,2,3)(.) \\
& {[(20,30,60)(+)(30,50,60)(-)(20,30,60)]} \\
& =\left\{\begin{array}{lc}
0, & x \leq 60 \\
{\left[-240+(21600+600 x)^{0.5}\right] / 300,} & 60 \leq x \leq 450 \\
{\left[740-(-3600+520 x)^{0.5}\right] / 260,} & 450 \leq x \leq 1060 \\
0, & x \geq 1060
\end{array}\right. \\
& \text { Or } Z_{2}=Z_{1}^{*}(+) C_{12}=Z_{1}^{*}(+) A_{2}(+) c_{2}(.) D_{2}=Z_{1}^{*}(+)(20,40,50)(+)(2,3,5)(.)(30,50,60) \\
& =\left\{\begin{array}{lc}
0, & x \leq 120 \\
{\left[-170+(4900+200 x)^{0.5}\right] / 100,} & 120 \leq x \leq 340 \\
{\left[490-(100+320 x)^{0.5}\right] / 160,} & 340 \leq x \leq 750 \\
0, & x \geq 750
\end{array}\right. \\
& \mu\left[Z_{1}^{*}(+) C_{12}\right]<\mu\left[Z_{0}(+) C_{02}\right] \\
& Z_{2}^{*}=\left[Z_{1}^{*}(+) C_{12}\right]
\end{aligned}
$$

The optimal production schedule is shown in Table X. 
Table X: The optimal production schedule.

\begin{tabular}{|l|l|l|}
\hline Period & 1 & 2 \\
\hline Production & $\mathrm{D}_{1}=(20,30,60)$ & $\mathrm{D}_{2}=(30,50,60)$ \\
\hline
\end{tabular}

\subsection{Comparison of the Two Solutions}

The solutions obtained by CDP and FDP are completely different. The former is represented by single numbers and has lost much of the original information. The latter is represented by fuzzy numbers and still retains the interval nature. As discussed earlier, this difference is very important and useful in practice.

These examples demonstrate the procedures and advantages of the general fuzzy approach using fuzzy numbers. Their results indicate that this proposed approach is an effective technique to solve the fuzzy MP-POM problems.

\section{DISCUSSION}

In this section three fuzzy MP-POM methods are compared and contrasted. They are: Sommer's method, Kacprzyk-Staniewski's (K-S's) method, and the method developed in this work.

\subsection{Sommer's Method}

Sommer [21] solved a numerical example of a fuzzy MP-POM problem to demonstrate his method. Mathematically his problem is described as follows:

The membership function of production level is:

$$
\mu_{C}\left(P_{i}\right)=\left\{\begin{array}{lc}
0, & \text { if } 0 \leq P_{i} \leq 60-10 i \\
-3+.5 i+P_{i} / 20, & \text { if } 60-10 i<P_{i} \leq 80-10 i \\
5-.5 i-P_{i} / 200, & \text { if } 80-10 i<P_{i} \leq 100-10 i \\
0, & \text { if } 95-10 i<P_{i}
\end{array}\right.
$$

The membership function of inventory level at the end of the management horizon is:

$$
\left(x_{N+1}\right)= \begin{cases}1-x_{N+1} / 20 & \text { if } 0 \leq x_{N+1} \leq 20 \\ 0 & \text { elsewhere }\end{cases}
$$

The management horizon is $\mathrm{N}=4$, the initial stock level is $\mathrm{x}_{1}=0$, and the demands are:

$D_{1}=45, D_{2}=50, D_{3}=45, D_{4}=60$.

In this situation, both demand and inventory are crisp numbers, but the two objectives "production level shall decrease as steadily as possible" and "the ending inventory level shall be as low as possible"- are fuzzy. It seems that the fuzzy environment of this production management problem is provided artificially rather than naturally. The reason for our employing a fuzzy set or a fuzzy number to denote a goal is that the goal cannot be precisely defined due to lack of accurate information. However, when exact data are available, such as demand and inventory in the above example, the decision maker should not set up a fuzzy objective, since it is invariably either suboptimal or infeasible.

In Sommer's example, if we think of the objective "the ending inventory level shall be as low as possible" as a constraint $\mathrm{x}_{\mathrm{N}+1}=0$, and his other objective "the production level shall decrease as steadily as possible" as a function of time $t, d p / d t=f(t)$, then the optimal production schedule can be easily obtained by crisp dynamic programming techniques.

\subsection{Kacprzyk - Staniewski's (K-S's) Method}

The conventional approaches to production and inventory control usually involve optimization of a performance index consisting of some cost-related terms. Kacprzyk and Staniewski [22] transformed the cost optimization problem into one of maintaining some desired inventory 
level. That is, they believe the average costs usually are known to be some functions of inventory and they are mostly isomorphic; the same applies to replenishment or production. In their example, it is assumed that $X=(1, \ldots, I 0) ; u, Y=I, \ldots, 5)$.

Given are the following:

the reference fuzzy inventory level $\mathrm{S}_{1}, \ldots, \mathrm{S}_{5}$;

the reference fuzzy replenishment $\mathrm{C}_{1}, \ldots, \mathrm{C}_{3}$;

the fuzzy demand $D$ and fuzzy goal $G$;

the fuzzy constraints $\mathrm{C}\left(\mathrm{S}_{1}\right), \ldots, \mathrm{C}\left(\mathrm{S}_{5}\right)$.

The above problem differs from Sommer's problem in that both its demand and inventory are fuzzy. This problem is more fuzzy and more practical than Sommer's problem in the sense of fuzzy sets theory. But from the practical point of view, it is too hard for the decision maker to provide the necessary and consistent data for determining the membership functions of the $S_{i}{ }^{\prime} s, C_{j}$ 's and $C\left(S_{i}\right)$ 's. This is especially true when $i$ and $j$ are big numbers.

As an alternative to using Kacprzyk and Staniewski's method, the problem can be solved by a procedure similar to our proposed general fuzzy approach as follows.

(a) use an appropriate fuzzy number, I $^{*}$, to indicate the "desired inventory level';

(b) use the transaction function $I^{*}=I_{t-1}(+) P_{t}(-) D_{t}$

and the given $\mathrm{I}_{0}$ and $\mathrm{D}_{\mathrm{t}}$ to determine $P_{t}, \mathrm{t}=\mathrm{I}, \ldots, \mathrm{N}$, where $\mathrm{P}_{\mathrm{t}}$ is the fuzzy replenishment or production to maintain the desired inventory level and satisfy the fuzzy demand;

(c) consider both $\mathrm{P}_{t}$ and the constraints on the replenishment or production simultaneously to determine the optimal replenishment policy;

(d) if the cost functions related to inventory level, $f\left(I_{t}\right)$ and replenishment level, $f\left(R_{t}\right)$ are known, we can use the total cost function $F=f\left(I_{t}\right)(+) f\left(R_{t}\right)$ to determine the optimal policy.

Following the above procedure, all the decision maker has to do is providing estimates for the desired inventory level, the replenishment constraints, and the cost functions.

\subsection{Our Proposed Method}

As shown in sections 4, 5, and 6 above, the fuzzy environment provided in our three examples is a natural one. We can obtain the necessary information on fuzzy costs and fuzzy demands by requiring the decision maker to provide the corresponding estimates. Our method not only gives the optimal fuzzy schedule but also the minimum fuzzy total cost. From a practical view point, these are very important and useful for production engineers and operations managers. Thus, we can summarize the essential features of the three fuzzy MPPOM methods in Table XI. 
Table XI: The three fuzzy MP-POM methods.

\begin{tabular}{|c|c|c|c|}
\hline & Sommer's & K-S's & Ours \\
\hline Goal & Fuzzy & Fuzzy & Fuzzy \\
\hline Constraint & Fuzzy & Fuzzy & Fuzzy \\
\hline Demand & Crisp & Fuzzy & Fuzzy \\
\hline Inventory & Crisp & Fuzzy & Fuzzy \\
\hline Costs & ------- & ------- & Fuzzy \\
\hline Other Conditions & Same & Same & Same \\
\hline Fuzzy Environment & Artificial & Natural & Natural \\
\hline Transition Equation & $I_{t+1}=I_{t}+P_{t}-D_{t}$ & $I_{t+1}=I_{t}+P_{t}-D_{t}$ & $I_{t+1}=I_{t}+P_{t}-D_{t}$ \\
\hline Optimization Function & $\operatorname{Max} . \mu_{G} \wedge \mu_{C}$ & $\operatorname{Max} . \mu_{G} \wedge \mu_{C}$ & Min. Total Cost \\
\hline Schedule & $\begin{array}{l}\text { Most Satisfaction of } \\
\text { Decision Maker }\end{array}$ & $\begin{array}{l}\text { Most Satisfaction of } \\
\text { Decision Maker }\end{array}$ & $\begin{array}{l}\text { Minimization of Total } \\
\text { Cost of Firm }\end{array}$ \\
\hline Data Collection & Medium & Difficult & Easy \\
\hline Computation & Simple & Tedious & Medium \\
\hline $\begin{array}{l}\text { Fuzzy Multistage Decision } \\
\text { Process }\end{array}$ & $\begin{array}{c}\text { Bellman \& Zadeh's } \\
\text { Model }\end{array}$ & $\begin{array}{c}\text { Bellman \& Zadeh's } \\
\text { Model }\end{array}$ & $\begin{array}{c}\text { General Fuzzy } \\
\text { Approach Using Fuzzy } \\
\text { Numbers }\end{array}$ \\
\hline
\end{tabular}

\section{CONCLUSIONS}

This work achieved the purpose of finding an effective method to solve the interval MP-POM problem while retaining all the original information through the general fuzzy approach, namely employing appropriate fuzzy numbers to represent the interval estimates in the multistage decision problems; using the operations of fuzzy numbers combined with dynamic programming to solve the problem; and determining the required minimum/maximum fuzzy number through fuzzy number ranking techniques.

Three MP-POM problems with fuzzy costs and/or fuzzy demands were solved by this approach. The optimal solutions of production schedule and total cost were indicated by fuzzy numbers. The main advantages of this approach are fuzzy representative solutions for the optimal production schedule as well as the minimum total cost in terms of interval units rather than single numbers. These solutions give the production engineers and the operations managers a clear picture about the interval units of production at each period and the interval units of the required minimum total cost, thus enabling them to manage the production flexibly and control the cost effectively.

On the other hand, the crisp model gave solutions by single numbers and lost a significant amount of useful information. In such a situation, the only option available to the engineers and managers is to produce the exact number of units given by the schedule and hope to incur the so called minimum total cost. Obviously, the proposed fuzzy approach is more realistic than the traditional crisp approach.

Another advantage of the proposed fuzzy approach is it partially overcomes the dimensionality difficulty of large scale problems. Thus a potential area for future research is to represent the data needed to solve real life multistage problems by fuzzy numbers and carry out the computations by dynamic programming using computers.

In this paper, the proposed approach was applied to solve problems with fuzzy goals and fuzzy constraints defined in the same space. Hence another promising area for further research is to extend this approach to solve problems with fuzzy goals and constraints defined in different spaces.

\section{REFERENCES}

[1] Corsano, G.; Aguirre, P.A.; Montagna, J.M. (2009). Multi-period Design and Planning of Multiproduct Batch Plants with Mixed-Product Campaigns, American Institute of Chemical Engineers (AIChE) Journal, Vol. 55, Issue 9, 2356-2369 
[2] Neiro, S.; Pinto, J. (2005). Multi-period Optimization for Production Management of Petroleum Refineries, Chemical Engineering Communications, Vol. 192, No. 1, 62-88

[3] Safaei, N.; Tavakkoli-Moghaddam, R. (2009). Integrated Multi-Period Cell Formation and Subcontracting Production Planning in Dynamic Cellular manufacturing Systems, International Journal of Production Economics, Vol. 120, Issue 2, 301-314

[4] Porkka, P.; Vepsalainen, A.P.J.; Kuula, M. (2003). Multi-period Production Planning Carrying Over Set-up Time, International Journal of Production Research, Vol. 41, Issue 6,1133-1148

[5] Moreno, M.S.; Montagna, J.M.; Iribarren, O.A. (2007). Multi-period Optimization for the Design and Planning of Multiproduct Batch Plants, Computers and Chemical Engineering, Vol. 31, Issue 9, 1159-1173

[6] Moreno, M.S.; Montagna, J.M. (2009). A Multi-period Model for Production Planning and Design in a Multiproduct Batch Environment, Mathematical and Computer Modelling, Vol. 49, Issue 7-8, 1372-1385

[7] El Hafsi, M.; Bai, S.X. (1998). Multi-period Production Planning with Demand and Cost Fluctuations, Journal of Mathematical and Computer Modelling, Vol. 28, No. 3, 103-119

[8] Feylizadeh, M.R.; Modarres, M.; Bagherpour, M. (2008). Optimal Crashing of Multi-period Multiproduct Production Planning Problems, World Applied Sciences Journal, Vol. 4, 499-505

[9] Li, Y.; Zhang, J.; Chen, J.; Cai, X. (2010). Optimal Solution Structure for Multi-period Production Planning with Returned Products Remanufacturing, Asia-Pacific Journal of Operational Research (APJOR), Vol. 27, Issue 5, 629-648

[10] Yildirim, I.; Tan, B.; Karaesmen, F. (2005). A Multi-period Stochastic Production Planning and Sourcing Problem with Service Level Constraints, OR Spectrum, Vol. 27, 471-489

[11] Filho, O.S.S. (1999). An Aggregate Production Planning Model with Demand under Uncertainty, Production Planning and Control, Vol. 10, No. 8, 745-756

[12] Kaminsky, P.; Swaminathan, J.M. (2004). Effective Heuristics for Capacitated Production Management with Multi-period Production and Demand with Forecast Band Refinement, Manufacturing and Service Operations Management, Vol. 6, No. 2, 184-194

[13] Kazancioglu, E.; Saitou, K. (2006). Multi-period Production Capacity Planning for Integrated Product and Production System Design, Proceedings of the IEEE Conference on Automation Science and Engineering, 3-8

[14] Sox, C.R.; Muckstadt, J.A. (1996). Multi-item, Multi-period Production Planning with Uncertain Demand, IIE Transactions, Vol. 28, No. 11, 891-900

[15] Nagasawa, H.; Nishiyama, N; Hitomi, K. (1982). Decision Analysis for Determining the Optimum Planning Horizon in Aggregate Production Planning, International Journal of Production Research, Vol. 20, No. 2, 243-254

[16] Kogan, K.; Portougal, V. (2006). Multi-period Aggregate Production Management in a Newsvendor Framework, Journal of Operational Research Society, Vol. 57, No. 4, 423-433

[17] Balakrishnan, J.; Cheng, C.H. (2007). Multi-period Planning and Uncertainty Issues in Cellular Manufacturing: A Review and Future Directions, European Journal of Operational Research, Vol. 177, Issue 1, 281-309

[18] Ryu, J.H. (2006). Multi-period Planning Strategies with Simultaneous Consideration of Demand Fluctuations and Capacity Expansion, Industrial and Engineering Chemistry Research, Vol. 45, No. 19, 6622-6625

[19] Wagner, H.M.; Whitin, T.M. (1958). A Dynamic Version of the Economic Lot Size Model, Management Science, Vol. 5, Issue 1, 89-96

[20] Kaufman, A.; Gupta, M.M. (1985). Introduction to Fuzzy Arithmetic: Theory and Applications, Van Nostrand Reinhold

[21] Sommer, G. (1981). Fuzzy Inventory Scheduling, Lasker, G.E. (Editor), Applied Systems and Cybernetics, Vol. 6, Pergamon, 3052-3060

[22] Kacprzyk, J.; Staniewski, P. (1982). Long-term Inventory Policy-making through Fuzzy Decision-making Models, Fuzzy Sets and Systems, Vol. 8, 117-132 